\title{
Cultivating Moral Competence of Chinese Undergraduates with KMDD-Sessions
}

\author{
Jing Zhang (Guangdong University of Foreign Studies)
}

In recent years, more and more Chinese scholars are focusing on research on moral cognition and moral judgment, but the research findings and theoretical frameworks remain limited in comparison to western countries (Zhang 2012). In today's China, many unexpected social phenomena have arisen due to a lack of morality. How to cultivate the moral judgment competence of the adolescents who are the future of the society is an urgent task for the society, the scholars, the parents and the educators. The author, as a moral education teacher, tries to find the situation of the Chinese adolescents' moral judgment competence using Lind's Moral Judgment Test (MJT) and cultivate Chinese adolescents' moral competency using Lind's Konstanz Method of Dilemma Discussion (KMDD).

Georg Lind, psychologist at the University of Konstanz, proposed the Dual-Aspect-Theory of moral behavior and development. On this basis he designed a new experimental measurement of moral competence (Lind 2002), the Moral Judgment Test (MJT) (Lind 2008a), and proposed a new method for fostering moral competence, the Konstanz Method of Dilemma Discussion (Lind 2008b), which has shown to be very effective. He also developed a workshop-seminar and on-the-job-training for teachers so that they can use the KMDD effectively and responsibly. The author has previously conducted two large MJT survey in Hubei province and Guangdong province of China, both of the C-scores are under 17, which is much lower than that in countries in Western Europe (Zhang 2012).

\section{Research question and hypotheses}

The KMDD is being used in various institutions of education in many countries, but not yet in China. The question is whether the KMDD is can also be used to foster moral-democratic competence of Chinese university students. Would Chinese students accept such kind of teaching and would it be as effective for cultivating and improving Chinese adolescents' moral judgment competence as it is in other countries? The KMDD method of fostering moral competence is quite different from the typical way of learning at the university in China. The typical teaching in Chinese universities is still by lectures with little interaction with the students. In contrast, in a KMDD-session the 
students have much time for interacting with one another in small groups, and discuss controversial issues in a plenary session. The teacher's role is confined to introducing the method, stimulating discussions by presenting a so-called "dilemma-story," and seeing after the rules of the discussion.

\section{Methods}

\subsection{Samples and procedure}

The author conducted seven KMDD-sessions with undergraduate students majoring in economics. Their age ranged from 19 to 21 years. Altogether 89 students took part. The participation was voluntary.

\subsection{Measurement Instruments}

The efficacy of the KMDD was measured using the validated and certified Chinese version of the "Moral Judgment Test" (MJT) by Lind (2008a). The MJT is the first test which allows for the simultaneous measure of cognitive and affective aspects of moral behavior: moral judgment competence and moral orientations. Lind used Kohlberg's six moral orientations to design arguments in favor and against the decisions in two moral dilemma stories (Workers and Doctor). It is a multivariate experiment which has three design-factors: the moral quality of an argument, opinion agreement, and the dilemma context. The participants must evaluate the decision-making of the protagonist in two dilemma-stories, and then rate arguments pro and contra this decision on a moral quality scale from "-4" (strongly reject) to "+4" (strongly agree). By rating the MJT's 24 arguments, the participants reveal the degree to which he or she lets moral concerns determine his or her rating-behavior. This degree is measured by the C-score, the MJT's index for moral judgment competence. For over 30 years, the MJT has been translated into 39 languages and used throughout more than 40 countries with over 200,000 participants in Europe, North and South America, Asia and Oceania, and achieved great success.

\subsection{Training as KMDD-Teacher}

According to Lind (2008), the KMDD method shows its pedagogical strength only when the teacher is fully trained and certified as a "KMDD-Teacher." It does not suffice that the teacher follows exactly the method as prescribed in the literature but that the teacher also understands the reasons behind, and that he or she can adapted the method competently to the participants and the subject field. So far, only fully certified KMDD-Teachers could achieve considerable and lasting increase of moral-democratic competence (Lind, personal communication). Professor Lind gives regularly one-week workshopseminars for teachers and offers also training and certification programs ${ }^{1}$.

${ }^{1}$ See: http://www.uni-konstanz.de/ag-moral 
In order to do this intervention study, the author participated in a oneweek KMDD workshop-seminar in Guangdong University of Foreign Studies in 2011. In this event, the participants did not only learn how to prepare, conduct, and evaluate KMDD-sessions but also took part in a sample KMDDsession themselves. As a result, their moral-democratic competence score (Cscore) increased impressively from pre-test to post-test by 5.1 points (Lind, personal communication). The author got the KMDD-Trainee certificate, allowing her to conduct KMDD-events herself. ${ }^{2}$

\subsection{Intervention with the KMDD}

The intervention utilized the Konstanz Method of Dilemma-Discussion (KMDD) developed by Georg Lind (2003; 2008b). KMDD-sessions were run with seven different groups of economy students. For these sessions modified versions of three dilemma stories were used: 1. "Joann's Former Boyfriend" (original author: Kay Hemmerling), 2. "Judge Steinberg's Decision” (Georg Lind) and 3. "John's Job" (Ernesto Bolanos). All stories were taken from the collection of stories by Professor Lind and translated into Chines by the author.

\begin{tabular}{|c|c|c|c|c|c|}
\hline $\begin{array}{c}\text { Group } \\
\text { (Dilemma } \\
\text { story) }\end{array}$ & Number & Date & $\begin{array}{c}\text { Group } \\
\text { (Dilemma } \\
\text { story) }\end{array}$ & Number & Date \\
\hline & 89 & & & 89 & \\
\hline $\begin{array}{c}1 \\
\text { (Joann) }\end{array}$ & 24 & $22 / 10 / 2012$ & $\begin{array}{c}4 \\
\text { (John's Job) }\end{array}$ & 34 & $29 / 10 / 2012$ \\
\hline $\begin{array}{c}2 \\
\text { (Judge } \\
\text { Steinberg) }\end{array}$ & 23 & $24 / 10 / 2012$ & $\begin{array}{c}5 \\
\text { (John's Job) }\end{array}$ & 13 & $31 / 10 / 2012$ \\
\hline \multirow[t]{2}{*}{$\begin{array}{c}3 \\
\text { (Joann) }\end{array}$} & 42 & $27 / 10 / 2012$ & $\begin{array}{c}6 \\
\text { (Judge } \\
\text { Steinberg) }\end{array}$ & 19 & $04 / 11 / 2012$ \\
\hline & & & $\begin{array}{c}7 \\
\text { (John's Job) }\end{array}$ & 23 & $06 / 11 / 2012$ \\
\hline & & ble1: I & 7 groups & & \\
\hline
\end{tabular}

From table1, we can see there were seven groups (sessions) together, and each participant took part in two KMDD-sessions. During the first, the 89 persons were divided into 3 groups: group_ 1 has 24 persons, group_2 has 23 persons, group_3 has 42 persons; during the second, they were divided into 4 groups: group_4 has 34persons, group_5 has 13 persons, group_6 has 19 persons, and group_7 has 23 persons. Group_1 and group_3 discussed the story of Joann's

2 Later, the author continued her training and also received the KMDD-Teacher certificate after this study. 
former boyfriend. Joan's dilemma is whether to go with her former boyfriend and stay overnight with him at a hotel. Group_2 and group_6 discussed the story of Judge Steinberg's Decision. Judge Steinberg's dilemma is whether to permit torturing the suspect in order to protect more people's lives. There are two main views of the dilemma: obeying the law or keeping social justice. Group_4, group_5 and group_7 discussed the story of John. John's dilemma is whether to submit a fund application making use of hypothetical information. The major is Economics, so they may face similar situations in future work.

\section{Results}

The interventions produced positive results. The participants' mean C-score is 19.38 before they took part in dilemma-discussion sessions and 19.70 after that. The increase was marginal, but the participants were interested in it very much. The study concludes the results as following:

\subsection{The participants' respond to the KMDD.}

The KMDD was very well received by the participants who were used to the very different typical Chinese way. They enjoyed the sessions using KMDD, students' learning and the classroom atmosphere. KMDD is a studentscentered approach which encourages students to speak out. During the discussion, the teacher's sole role is to listen intensively rather than to be an authority who tells the students which choice was right and moral or impose moral ideas on them. Our traditional way is seen as a Duck-stuffing type of teaching. Teachers will pour knowledge into students' head and speak at the whole class while students listen and write down notes; there are no discussions between teachers and students or students themselves. Teachers mostly play a role of authority in class and students are only told about 'what' but not 'why' and 'how'. "This teaching way also leads to less effective student learning. They are not used to prepare lessons before class and they are used to wait for teachers giving them answers in the class. The result of the Duckstuffing type of teaching is that students are shy to speak out, do not express their own thoughts and ideas, are not actively or consciously learning and lack of the ability of practice and innovative. That's why we say Chinese students are excellent at examinations but poorly at creation and practice.

Using KMDD, the classroom atmosphere is relaxing and vivid. Students can sit around the table in class; it is good for students to discuss with each other. In China, the classroom atmosphere is rigid, teachers stand on the platform in the front of the classroom, and students sit quietly in order. Some teachers will encourage the students to discuss in the class, but the students are not used to the way to learn, some will discuss with the classmates around them, some will reading their books or continue with their own business. Seldom students would like to share opinions with others in the class. So the 
atmosphere of most classes is tedious and dull. KMDD-dilemma discussions are not only seen to raise the moral judgment competence of the students, but also to make them more interested in learning the subjects of the curriculum and improve the learning climate in the classroom. Most participants became more active in other classes since they took part in KMDD-sessions. KMDDtraining is good not only to improve the participants' moral judgment but also the quality of classes.

\subsection{The clues and feedbacks got from the students for the future applications on KMDD.}

3.2.1 Group sizes may affect the efficacy of the KMDD. This area will be pursued more systematically in future research. The participants' feedback suggested that the participants had little chances to speak in big groups with above 34 persons (group_3 and group_4), but the discussion was more vivid. In small groups with under 20 persons (group_5 and group_6), the participants have more chances to speak but the discussion is less vivid. The participants' feeling of excitement or challenge was not high, so the majority may not have profited as much as they could because the shared opinions are limited. The participants of group_1, group_2 and group_7 with 20 to 30 persons felt better. They had opportunities to speak and the discussion was vivid, so they could learn more from the session.

3.2.2 The so-called Ping-Pong principle is an effective method in the discussion phase. Groups with different opinions sit at each side of the classroom, when one person of some side speak over, he or she will choose the next one from the persons who raised up their hands of the opposite group, then it continues with Ping-Pong principle. It can make the discussion go on smoothly, avoiding the noisy scene of debate competition. Participants also mentioned some limitations. For example, some participants had no chance to speak if they are not be chosen by the speaker or they cannot give the answer while being required for answering by others directly unless he or she just has the chance to speak. I think this is in fact Professor Lind's intention that encourages the participants to continue the discussion after the limited discussion time.

3.2.3 The phase of "nominating the best arguments of the opposite group" was truely welcomed by the participants. They thought they learned how to respect people who hold different points of view from them, even though they might never agree with other person's ideas, or even though they might think other person's ideas are irrational or childish. They learned to deal with the contradictions in a peaceful way.

3.2.4 KMDD-teachers should know how to deal with a vote that result in less than $25 \%$ of the participants being on one side. In the discussion of John's story, the vote result was $22: 2$, so the session should be stopped right there at this situation. Professor Lind gave the following advice: Do not 
announce a "discussion" so that the participants are not disappointed that no discussion takes place. And never let anyone simulate an opinion in order to have enough "opponents". Simulated opinions undermine learning because in simulated opinions no moral emotion is involved. The two persons may not have dared to show how frightened they were. And the majority may have also not profited as much as they could because the two opponents are not a big enough challenge. So they will probably not develop their moral competence.

3.2.5 Participants' votes may be affected by the decision of the story's main character. In the discussion of the story of Judge Steinberg's Decision, when Steinberg gives permission to torture the suspect, the persons of group 2 who agreed with him are more than that who disagreed. That is, more participants thought keeping justices was the most important of the society. But when the teacher changed Judge Steinberg's decision-refusing to torture the suspect, the persons of group_6 who agreed with him were also more than that who disagreed. That is, more participants thought obeying the laws was the most important.

It's the same situation of group_4 and group_7, they discussed the story of John. In the discussion of group_4, John decides to submit a fund application using hypothetical information. The author gave some clarification on the advantages of his decision: getting welfare for the local disadvantage groups, keeping his first job through his families' effort. The voting result is 23 persons agreed with his decision and 11 persons disagreed with him. In the group_7, the author changed John's decision - not submitting the fund application with hypothetical information. I then gave some good clarification on his decision: he is responsible and honest to the society and his job. The voting result was 16 persons agreed with his decision and 7 persons disagreed with him.

3.2.6 There may be a problem with using the English versions of dilemma-stories. Some participants will look up the dictionary or discuss with others for unknown words, which may affect the whole phase of KMDDsession. Additionally, some English words may lead to ambiguities, so the Chinese version may be better.

\subsection{Possible reasons of the participants' small gain of moral competence.}

The author was certified as a KMDD-Trainee but not yet as a KMDD-Teacher when she ran the KMDD-sessions. Experience and expertise in using KMDD method is important for getting high gains with the KMDD (Lind, 2009). The review of the sessions revealed that they were too short (60 minutes instead of the proposed 90 minutes). This means the participants may have had too little time to elaborate the information offered in the sessions. 


\section{Conclusions and Suggestions}

To sum up, KMDD is may be an effective method to cultivate and improve Chinese adolescents' moral judgment competence. Although the gains of the moral competence measure were small, overall the intervention produced positive results and the participants showed great interest in KMDD which is very different from Chinese typical way of teaching. They liked the way the teacher's giving the lesson, the opportunity for reflection and discussion and the classroom atmosphere. The author also collected some feedback from the participants, which may be useful in informing future application and research on KMDD in China.

As shown in many other intervention studies, KMDD has proven to be a very effective method for fostering students' moral competence, that is, their ability to solve moral conflicts on the basis of shared moral principles through thinking and dialogue rather than through violence, fraud or abuse of power (Lind 2008). Therefore, KMDD can be valuable, especially for building a harmonious society. When a society is developing diversity and variability as in China today, it can be a useful tool to aid the present "Education Revolution". For this end, however, it is also necessary to train and certify KMDD-Teachers who can use this method effectively.

\section{Literature ${ }^{3}$}

Kohlberg, L. 1975. The Cognitive-Developmental Approach to Moral Education [J]. Phi Delta Kappa 56, 670-677

—, 1984. Essays on Moral Development: Vol. 2. The Psychology of Moral Development. San Francisco, CA: Harper \& Row.

Lind, G., 2006. Effective Moral Education: The Konstanz Method of Dilemma Discussion [J]. Hellenic Journal of Psychology 3, 189-196.

—, 2008a. "The Meaning and Measurement of Moral Judgment Competence Revisited - A Dual-Aspect Model”. In: D. Fasko \& W. Willis, (Eds.), Contemporary Philosophical and Psychological Perspectives on Moral Development and Education. Cresskill. NJ: Hampton Press, 185-220.

—, 2008b. "Teaching Students to Speak Up and to Listen to Others: Cultivating Moral Democratic Competencies". In: D.E. Lund \& P.R. Carr, (Eds.), Doing Democracy and Social Justice in Education: Political Literacy for All Students. New York: Peter Lang Publishing, 319-335.

—, 2009. Moral ist lehrbar. Handbuch zur Theorie und Praxis moralischer und demokratischer Bildung. [Morality Can Be Taught. Handbook on Theory and Practice of Moral and Democratic Education]. München: Oldenbourg.

\footnotetext{
3 Note: Lind's KMDD Training Manual, from which several quotes are taken, is not published.
} 
—, 2011. "Moral Education. Building on Ideals and Fostering Competencies". Contemporary Issues. Education 2, 1, 45-59.

Zhang, J. 2012. "Factors of Chinese Adolescents' Moral Judgment Competence". Ethics in Progress Quarterly 3, 2012, 83-95.

Zhang, J., Yang, S. 2012. "The Research and Development of Moral Judgment Test in China". In: E. Nowak. D. Schrader, B. Zizek, (Eds.), Educating Competencies for Democracy. New York: Peter Lang Publishing, 47-58. 
Jing Zhang (School of Marxism, Guangdong University of Foreign Studies;

School of Marxism, Wuhan University)

\title{
Cultivating Moral Competence of Chinese Undergraduates with KMDD-Session
}

\begin{abstract}
This study describes the results of interventions with the Konstanz Method of Dilemma Discussion (KMDD) by Georg Lind, with 89 economics undergraduate participants sampled from Guangdong province. The participants' mean C-score in the Moral Judgment Test increased only a little because of the teacher's little experience in using KMDD, but otherwise the intervention produced good results: the participants showed great interest in KMDD although this teaching method is very different from the typical Chinese teaching, and they enjoyed the KMDD-sessions and the classroom atmosphere created through it. Students' feedback will be useful for future application and research on KMDD in China.
\end{abstract}

Key words: Konstanz Method of Dilemma Discussion; Moral Judgment Test; moral and democratic education

Ethics in Progress (ISSN 2084-9257). Vol. 4 (2013). No. 1. 48-56. 